\title{
Inheritance of Flowering, Maturity, Fruit Yield, and Winter Hardiness of Sea Buckthorn (Hippophae rhamnoides)
}

\author{
Xurong Tang ${ }^{1}$ and Peter M.A. Tigerstedt \\ Department of Applied Biology, University of Helsinki, 00014 Helsinki, Finland
}

ADDITIONAL INDEX wORDs. genetic correlation, heritability, heterosis, phenotypic correlation.

\begin{abstract}
Eight characters relating to flowering and maturity, berry yield, and winter hardiness were estimated on the basis of intersubspecific or interprovenance hybrids to determine heterosis, heritability, and genetic and phenotypic correlations in sea buckthorn (Hippophae rhamnoides L.). Two provenances of ssp. rhamnoides, one of Finnish (Fin) and one of Danish (Dan) origin, were dominant to ssp. sinensis and Russian derived provenances (ssp. turkestanica) for most characters related to flowering or maturity. This tendency for dominance or overdominance also extended to berry yield and winter hardiness, except for hybrids between Finnish origins and Siberian (ssp. mongolica) origins. The start of maturity (Ms) and half maturity $(\mathrm{Mh})$ showed the highest heritabilities $\left(\mathrm{h}^{2}=0.88\right.$ and 0.81 , respectively). The hybrids were matroclinal, suggesting that Ms and Mh may be sex-linked or cytoplasmically inherited characters. Winter hardiness was the trait with the lowest heritability $\left(h^{2}=0.02\right)$, suggesting that the climate at the testing site was not severe enough to differentiate variation among half sibs or full sibs derived from Fin $x$ Dan, which on average proved hardier than the native parental provenance Fin. Full maturity (Mf) showed a moderate heritability but was stable across 2 years $\left(r_{B}=\right.$ 1). High genetic correlations among $M f, M s$, and $M h\left(r_{G}=0.94,0.96\right.$, and 1.00, respectively) suggest that these characters were controlled by the same genes. Yield showed a negative genetic correlation with all characters pertaining to flowering and maturity, indicating that selection for early flowering or early maturity should result in a gain in yield.
\end{abstract}

Recently, the high nutritional and medicinal values of sea buckthorn (Hippophae rhamnoides) have engendered a special interest in studying, domesticating, and breeding this species in Eurasia and North America (Yao, 1994). Large variability in morphological, chemical, and sensory attributes has been revealed among subspecies, populations, and individuals of sea buckthorn, rendering this species an ideal subject for genetic improvement of these characters. Tang and Tigerstedt (2001) characterized the berries of ssp. rhamnoides as having low concentrations of vitamin $\mathrm{C}$ and sugar, and large berry size compared with ssp. sinensis. Crosses between subspecies showed more potential for improving nutritional characteristics of sea buckthorn than crosses within the local Finnish subspecies. Moreover, studies of Tang et al. (2001) suggested that crosses involving different subspecies or disparate provenances could help improve the flavor of sea buckthorn juice.

In sea buckthorn, Yao and Tigerstedt (1995) found a clinal variation with respect to latitude in time of budbreak and growth cessation as well as in winter hardiness. The higher the latitude of origin of populations of ssp. rhamnoides, the earlier growth began and ceased, and the hardier the plants. The same tendency has been documented also in, e.g., apple [Malus sylvestris (L.) Mill var. domestica (Borkh.) Mansf.] (Nesterov, 1983) and bilberry (Vaccinium myrtillus L.) (Vanninen et al., 1988).

Hippophae rhamnoides ssp. rhamnoides is the most northerly distributed of the subspecies, and hence shows the best adaptation to high latitude climates. Improving the nutritional and sensory properties of ssp. rhamnoides through crosses with other subspe-

Received for publication 18 Dec. 2000. Accepted for publication 19 June 2001 This research was supported financially by the Foundation of Research in Natural Resources, Finland. The authors thank Peter Joy, Pertti Pulkkinen, and Matti Haapanen for their valuable suggestions during preparation of this manuscript. The cost of publishing this paper was defrayed in part by the payment of page charges. Under postal regulations, this paper therefore must be hereby marked advertisement solely to indicate this fact.

${ }^{1}$ Corresponding author; xurong.tang@helsinki.fi. cies, or even via intrasubspecific crosses involving southern ecotypes, must ensure that the hybrids are adapted to the high latitude climatic environments where they are to be cultivated. These environments are characterized by a short growing season with a low thermal sum (Väinölä and Joy, 1996). Large withinand between-season fluctuations impose considerable demands for early fruit maturation. Late spring frosts pose a challenge for flower survival. In addition, exceptionally hard but unpredictable winters frequently threaten survival of the whole plant. All these factors relate directly to yield (Lindèn et al. 1999). Breeding plants for late-flowering coupled with early ripening provides a major strategy for northern regions. To summarize, flowering time, fruit earliness, and winter hardiness are important considerations in formulating fruit breeding strategies in high latitude regions.

To our knowledge, no information concerning flowering, maturity related characters or their genetic and phenotypic correlations have been reported for sea buckthorn. The literature pertaining to yield and winter hardiness is also quite limited. In this study, evidence is presented of heterosis in hybrids from crosses of disparate origins, heritabilities, and genetic and phenotypic correlations for offspring from crosses between different provenances within ssp. rhamnoides. Such knowledge should be useful and of interest to breeders planning a breeding program or wishing to improve related characters in sea buckthorn.

\section{Materials and Methods}

Trial DESIGN. The materials used in this study were taken from a breeding orchard at Arabia, Helsinki, described previously (Tang and Tigerstedt, 2001; Yao and Tigerstedt, 1995). It was established in Spring 1990 and 1991 with 1-year-old seedlings and comprised initially of 4000 bushes. Sea buckthorn is a dioecious plant. Up to the time of observation, around 2000 bushes were growing in the orchard after removal of most of the male individuals and without systematic management. Factorial 
design (Becker, 1992) or North Carolina design 2 (Hill, et al. 1998) was applied for individuals representing an interprovenance hybridization within a subspecies, in other words, an intrasubspecific hybridization. Open-pollinated seedlings from Finnish, Danish, and Chinese origins were used as controls. Only female bushes were observed.

The breeding orchard was originally arranged in a randomized complete block design with noncontiguous plots (Yao and Tigerstedt, 1995). Since the female individuals were distributed randomly, the present trial was considered as a completely randomized design.

In the present study, progenies from Fin $x$ Dan combinations were used for calculating heritabilities, and genetic and phenotypic correlations. Offspring from both interprovenance hybrids and intersubspecific hybrids were analyzed for heterosis.

Measurements. In 1999, observations were made on flowering and berry maturity every other day. The start of flowering (Fs) was determined as the number of days, from 1 May, at which the flower stigmas of a particular bush elongated enough to be visible. The end of flowering $(\mathrm{Fe})$ was recorded when all the stigmas had disappeared or wilted. The duration of flowering $(\mathrm{Fd})$ was calculated as the difference between Fe and Fs. The start of maturity (Ms) was determined as the number of days, from 1 May, on which $1 \%$ of berries on a bush changed color, while half maturity (Mh) and full maturity (Mf) represented the time when half and all berries changed color, respectively. Duration of berry maturation (Md) was calculated as the difference between Mf and Ms, while entire duration of reproductive time ( $\mathrm{Rt}$ ) was taken as the difference between Mf and Fs.

Winter hardiness, investigated during the observation of flowering, was scored on a scale of 1 to 5 with 1 indicating that most of the shoots which had developed during the previous summer in the upper canopy had died without producing any of the current season's young shoots and 5 representing no winter injury. Berry yield, assessed after maturation, was scored visually on a scale of 0 to 5 with 0 indicating no yield and 5 for the highest level of yield. In 2000, Mf and fruit yield were observed or assessed in the same way as in 1999.

Statistical analyses. Progenies of Fin $x$ Dan were composed of two disconnected unbalanced sets $(8$ female $\times 3$ male and 6 female $\times 5$ male). Each set had unequal parental contributions and the different individual crosses contained unequal number of progenies. According to Falconer and Mackay (1996), unbalanced data can be treated as a single set of data at the expense of losing a degree of freedom, and restricted maximum likelihood (REML) is the most appropriate method in such a case. The estimate was based on the mixed linear model for 1-year data:

$\mathrm{Y}=\mathrm{u}+\mathrm{X}_{\mathrm{f}}+\mathrm{X}_{\mathrm{m}}+\mathrm{X}_{\mathrm{fm}}+\mathrm{e}$

where $\mathrm{Y}$ is the vector of observations; $\mathrm{u}$ is the vector of fixed effects, Xf, Xm, and Xfm are random vectors representing maternal, paternal effects, and interaction between maternal and paternal effects, respectively; and e is a random vector of residuals. All vectors on the right hand side of Eq. [1] are related to Y. The combined analysis on 2-year data for Mf and yield was also based on Eq. [1] by including the effects of years: $Y=u+X_{y}+$ $\mathrm{X}_{\mathrm{f}}+\mathrm{X}_{\mathrm{m}}+\mathrm{X}_{\mathrm{fm}}+\mathrm{X}_{\mathrm{fy}}+\mathrm{X}_{\mathrm{my}}+\mathrm{X}_{\mathrm{fmy}}+\mathrm{e}$, where the length of the vector on the basis of one year's data was doubled. The computation was carried out under PROC MIXED of SAS software (SAS Institute, 1996). Variance components and corresponding standard errors due to maternal effects $\left(\sigma_{\mathrm{f}}^{2}\right)$, paternal effects $\left(\sigma_{\mathrm{m}}^{2}\right)$, interaction of maternal and paternal effects $\left(\sigma_{\text {fm }}^{2}\right)$, and residuals $\left(\sigma_{\mathrm{e}}^{2}\right)$ were obtained for results of 1 year. The effect of years was estimated as a fixed effect, while effects of interactions between years and maternal and paternal effects $\left(\sigma_{\text {my }}^{2}, \sigma_{\text {fy }}^{2}, \sigma_{\text {fmy }}^{2}\right)$ were obtained as random effects for combined analysis. Since the crosses were originally made between individuals from two different provenances, the inbreeding depression was taken as nil in estimating heritabilities in the narrow sense, following Becker (1992): $\mathrm{h}_{\mathrm{m}}{ }_{\mathrm{m}}=$ $4 \sigma^{2}{ }_{m} /\left(\sigma_{m}^{2}+\sigma_{f}^{2}+\sigma_{\text {fm }}^{2}+\sigma^{2}{ }_{m y}+\sigma_{\text {fy }}^{2}+\sigma_{\text {fmy }}^{2}+\sigma^{2}\right) ; h_{f}^{2}=4 \sigma_{f}^{2} /\left(\sigma_{m}^{2}+\right.$ $\sigma_{\mathrm{f}}^{2}+\sigma_{\mathrm{fm}}^{2}+\sigma_{\text {my }}^{2}+\sigma_{\text {fy }}^{2}+\sigma_{\text {fmy }}^{2}+\sigma_{\mathrm{e}}^{2}$ ), where $\sigma_{\text {my }}^{2}, \sigma_{\text {fy }}^{2}, \sigma_{\text {fmy }}^{2}=0$ for the analysis of results of 1 year. The sEs of heritability estimates, $\mathrm{SE}\left(\mathrm{h}_{\mathrm{f}}^{2}\right)$, and $\mathrm{SE}\left(\mathrm{h}_{\mathrm{m}}^{2}\right)$ for maternal and paternal effects, respectively, were estimated in the same way as heritability. The factorial crosses were unbalanced (more females than males) and a weighted average for the variance components was used to calculate the overall heritability. In the present study, the calculations was made by weighing the female and male variance components with their corresponding numbers as follows: $h^{2}=4\left(n_{f} \sigma_{f}^{2}+n_{m} \sigma_{m}^{2}\right) /\left(n_{f}\right.$ $\left.+\mathrm{n}_{\mathrm{m}}\right)\left(\sigma_{\mathrm{f}}^{2}+\sigma_{\mathrm{m}}^{2}+\sigma_{\mathrm{fm}}^{2}+\sigma_{\mathrm{fy}}^{2}+\sigma_{\mathrm{my}}^{2}+\sigma_{\mathrm{fmy}}^{2}+\sigma_{\mathrm{e}}^{2}\right)$, where $\mathrm{n}_{\mathrm{f}}$ and $\mathrm{n}_{\mathrm{m}}$ are corresponding numbers for female and male parents. The $\mathrm{SE}$ values of pooled estimates of $\mathrm{h}^{2}$ were according to Becker (1992)

Table 1. Variation of mean dates counted from 1 May for flowering and maturity related characters, and durations of these characters among different crosses and some of their parental controls (SD in parentheses).

\begin{tabular}{|c|c|c|c|c|c|c|c|c|c|c|}
\hline $\begin{array}{l}\text { Origin }^{\mathrm{z}} \text { or } \\
\text { (entries) }\end{array}$ & $\begin{array}{l}\text { Subspecies or } \\
\text { hybridizations }\end{array}$ & Individual & $\begin{array}{c}\text { Flowering } \\
\text { start }\end{array}$ & $\begin{array}{c}\text { Flowering } \\
\text { end }\end{array}$ & $\begin{array}{c}\text { Flowering } \\
\text { duration }\end{array}$ & $\begin{array}{c}\text { Maturity } \\
\text { start }\end{array}$ & $\begin{array}{c}\text { Half } \\
\text { maturity }\end{array}$ & $\begin{array}{c}\text { Full } \\
\text { maturity }\end{array}$ & $\begin{array}{l}\text { Maturity } \\
\text { duration }\end{array}$ & $\begin{array}{c}\text { Reproductive } \\
\text { duration }\end{array}$ \\
\hline (Chi)nese & sinensis & 11 & $7.5 c^{y}(3.6)$ & $29.1 \mathrm{~d}(4.4)$ & $21.5 \mathrm{c}(1.5)$ & 106.4 a (8.6) & $113.5 \mathrm{a}(11.5)$ & $128.0 \mathrm{a}(14.6)$ & $22.8 \mathrm{ab}(6.4)$ & $120.5 \mathrm{a}(16.3)$ \\
\hline (Dan)ish & rhamnoides & 36 & $16.6 \mathrm{a}(3.1)$ & $43.8 \mathrm{a}(3.4)$ & $27.3 \mathrm{a}(3.1)$ & 105.7 a (5.5) & $112.8 \mathrm{a}(6.2)$ & $128.3 \mathrm{a}(10.5)$ & $22.6 \mathrm{ab}(7.0)$ & $111.7 \mathrm{~b}(10.6)$ \\
\hline (Fin)nish & rhamnoides & 48 & $9.6 \mathrm{c}(3.8)$ & $33.5 \mathrm{~cd}(3.5)$ & $24.1 \mathrm{abc}(2.9)$ & $92.9 \mathrm{~d}(5.3)$ & $97.2 \mathrm{de}(5.7)$ & $106.8 \mathrm{~cd}(6.9)$ & $14.0 \mathrm{c}(3.0)$ & $97.5 \mathrm{~d}(6.6)$ \\
\hline Fin $x$ Dan & rhamnoides & 312 & $12.0 \mathrm{~b}(3.9)$ & $37.7 \mathrm{~b}(4.6)$ & $25.7 \mathrm{ab}(3.7)$ & 98.5 c (3.7) & $103.0 \mathrm{bc}(4.4)$ & $115.3 \mathrm{~b}(5.8)$ & $16.8 \mathrm{c}(3.7)$ & $103.2 \mathrm{c}(5.5)$ \\
\hline \multirow{3}{*}{$\begin{array}{l}\text { Dan x Chi } \\
\text { (Rus)sian x Dan }\end{array}$} & female $x$ male & 13 & 15.8 a (5.9) & $39.9 \mathrm{ab}(6.5)$ & $24.1 \mathrm{abc}(3.5)$ & $105.4 \mathrm{a}(4.5)$ & 113.6 a (6.2) & 129.6 a (9.6) & 24.2 a (7.5) & $113.8 \mathrm{ab}(11.1)$ \\
\hline & \multicolumn{10}{|l|}{ turkestanica (female) } \\
\hline & $\mathrm{x}$ male & 7 & $17.1 \mathrm{a}(2.8)$ & $45.2 \mathrm{a}(2.8)$ & $28.5 \mathrm{a}(3.0)$ & $103.6 \mathrm{ab}(4.5)$ & $108.1 \mathrm{ab}(3.1)$ & 125.9 a (7.9) & $22.3 \mathrm{ab}(6.4)$ & 108.7 bc (7.9) \\
\hline Fin $x$ Chi & female $x$ male & 9 & $6.3 \mathrm{c}(4.1)$ & $28.6 \mathrm{~d}(4.8)$ & $22.2 \mathrm{bc}(2.0)$ & $95.1 \mathrm{~cd}(4.3)$ & $99.8 \operatorname{cd}(5.6)$ & $113.3 \mathrm{bc}(7.2)$ & $18.2 \mathrm{bc}(3.8)$ & $107.0 \mathrm{bc}(8.4)$ \\
\hline Rus $x$ Fin & female $x$ male & 17 & $10.9 \mathrm{bc}(3.8)$ & $37.0 \mathrm{bc}(4.9)$ & $26.1 \mathrm{ab}(4.1)$ & 99.1 bc (3.0) & $103.7 \mathrm{bc}(3.5)$ & $115.3 \mathrm{~b}(3.7)$ & $16.2 \mathrm{c}(2.0)$ & 104.4 c (4.2) \\
\hline \multirow[t]{2}{*}{ Siberian $\mathrm{x}$ Fin } & \multicolumn{10}{|l|}{ mongolica (female) } \\
\hline & $\mathrm{x}$ male & 15 & $8.3 \mathrm{c}(2.9)$ & $30.1 \mathrm{~d}(5.7)$ & $21.9 \mathrm{c}(5.5)$ & $89.7 \mathrm{~d}(2.6)$ & $92.8 \mathrm{e}(3.4)$ & $103.3 \mathrm{~d}(5.0)$ & $13.7 \mathrm{c}(3.2)$ & $95.1 \mathrm{~d}(4.9)$ \\
\hline
\end{tabular}

${ }^{\mathrm{z} C o n t r o l ~ C h i: ~ o p e n ~ p o l l i n a t e d ~ s e e d s ~ f r o m ~ C h i n a ; ~ c o n t r o l ~ D a n: ~ o p e n ~ p o l l i n a t e d ~ s e e d s ~ f r o m ~ a ~ D a n i s h ~ o r i g i n ~ c u l t i v a t e d ~ i n ~ H e l s i n k i, ~ S o u t h e r n ~ F i n l a n d ; ~}$ control Fin: open pollinated seeds from different populations from Finland. Hybridizations, Sib X Fin, Rus X Fin, Rus X Dan, were made in west Russia and the others in Finland.

yMean separation within columns by Tukey's studentized range test, $P<0.05$. 
for unequal sample sizes. Stability of progenies across 2 years followed the formula of Yamada (1962): $r_{B}=\sigma_{g}^{2} /\left(\sigma_{g}^{2}+\sigma_{g y}^{2}\right)$, where $g$ represents additive genetic effect and gy the genetic by year effects.

The genetic and phenotypic correlations estimated on the basis of Eq. [1] extended to multiple traits investigated in 1999, but without the vector of interaction. The multivariate analysis of variance (MANOVA) statement of the PROC GLM of the SAS software provided the sums of cross products. The options HTYPE $=3$ and ETYPE $=3$ were used to produce the matrices with the TYPE III sums of cross products for maternal, paternal effects, and error, which could be used to estimate corresponding covariance matrices among characters. The overall genetic or phenotypic correlations were weighted in the same way as the estimate of overall heritability. Thus, the genetic and phenotypic correlations were estimated following Becker (1992) with modification: $\mathrm{r}_{\mathrm{G}}=\left(\mathrm{n}_{\mathrm{f}} \operatorname{cov}_{\mathrm{xy}(\mathrm{f})}+\mathrm{n}_{\mathrm{m}} \operatorname{cov}_{\mathrm{xy}(\mathrm{m})}\right) /\left[\left(\mathrm{n}_{\mathrm{f}}+\mathrm{n}_{\mathrm{m}}\right)\left(\sigma_{\mathrm{x}(\mathrm{f})}^{2}+\sigma_{\mathrm{x}(\mathrm{m})}^{2}\right)^{1 / 2}\left(\sigma_{\mathrm{y}(\mathrm{f})}^{2}\right.\right.$

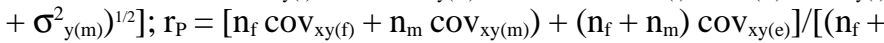
$\left.\left.\left.\mathrm{n}_{\mathrm{m}}\right) \sigma_{\mathrm{x}(\mathrm{f})}^{2}+\sigma_{\mathrm{x}(\mathrm{m})}^{2}+\sigma_{\mathrm{x}(\mathrm{e})}^{1 / 2}\right)\left(\sigma_{\mathrm{y}(\mathrm{f})}^{2}+\sigma_{\mathrm{y}(\mathrm{m})}^{2}+\sigma_{\mathrm{y}(\mathrm{e})}^{2}\right)^{1 / 2}\right]$, where subscripts $\mathrm{G}$ and $\mathrm{P}$ represent genetic and phenotypic, $\mathrm{x}$ and $\mathrm{y}$ two different characters; and f, m, and e maternal, paternal, and error effects, respectively.

The SE of the genetic correlations was computed following Falconer and Mackay (1996): $\operatorname{SE}\left(\mathrm{r}_{\mathrm{G}}\right)=\left(1-\mathrm{r}_{\mathrm{G}}{ }_{\mathrm{G}}\left[\operatorname{SE}\left(\mathrm{h}^{2}{ }_{\mathrm{x}}\right) \operatorname{SE}\left(\mathrm{h}^{2}{ }_{\mathrm{y}}\right) /\right.\right.$ $\left.\left(2 h^{2}{ }_{x} h_{y}^{2}\right)\right]^{1 / 2}$, where $h_{x}{ }^{2}$ and $h_{y}{ }^{2}$ are the heritabilities of the characters $\mathrm{x}$ and $\mathrm{y}$ respectively, $\mathrm{SE}\left(\mathrm{h}_{\mathrm{x}}{ }^{2}\right)$ and $\mathrm{SE}\left(\mathrm{h}_{\mathrm{y}}{ }^{2}\right)$ are the respective $\mathrm{SES}$ of $\mathrm{h}_{\mathrm{x}}{ }^{2}$ and $\mathrm{h}_{\mathrm{y}}{ }^{2}$, while $\mathrm{r}_{\mathrm{G}}$ is the genetic correlation between characters $\mathrm{x}$ and $\mathrm{y}$.

Differences among studied characters of hybrid groups and parental controls were detected by using analyses of variance (ANOVA) with SAS software under PROC GLM (SAS Inst. 1996). Significant differences among means detected by ANOVA were separated by Tukey's studentized range (HSD) test at $P=$ 0.05 .

\section{Results and Discussion}

Group Variation. The variation of characters related to flowering and maturation among intra and intersubspecific progenies and in the parental provenances used as controls are presented in Table 1. The Finnish parental provenance (Fin) was significantly earlier, or showed shorter periods to phenological events, than the Danish (Dan) for all characters except duration of flowering $(\mathrm{Fd})$. Their progeny, Fin $x$ Dan, fell between the mean values of the parentals for all characters examined. This indicates that characters related to flowering and maturity were quantitatively inherited in within-subspecies crosses.

The Chinese parental control (Chi), representing ssp. sinensis, flowered significantly earlier than Dan but matured later than Fin. However, the intersubspecific hybrids, Fin $x$ Chi and Dan $x$ Chi, did not differ significantly from the respective Dan or Fin parentals for any of the characters studied. This suggests that Dan and Fin were dominant to Chi in characters related to flowering and maturity, at least when their hybrids are grown in a high latitude region. This tendency, which also extended to most characters of other intersubspecific hybrids involving Dan or Fin, highlighted that flower- ing and maturity related characters could be predicted satisfactorily in intersubspecific hybridizations from parental means.

On the basis of the same plant material, Yao and Tigerstedt (1995) found that the parental control, Chi, showed the earliest budbreak, and Dan the latest. The same tendency, reflected in the start of flowering (Fs), implies that earlier budbreak is associated with earlier flowering. Meanwhile, the consistency of our study with that of Yao and Tigerstedt (1995) for winter hardiness indicates the presence of a high juvenile-mature correlation for this character.

Significant differences were detected for yield and hardiness among different hybrid groups and parental controls (Fig. 1). The parental Chi suffered the worst winter damage $(\mathrm{Wd})$ and had the lowest yield, followed by group Siberian (Sib) $x$ Fin. The intrasubspecific hybrids, Fin $x$ Dan, showed the lowest $\mathrm{Wd}$ and the highest yield. The phenotypic correlation between fruit yield and $\mathrm{Wd}(r=0.95)$ is strong and highly significant $(P=0.001)$ on the basis of group means. According to Tigerstedt (1994), in plants where seeds or berries are the products used, yield is subject to adaptation under marginal conditions. This tendency is supported by our finding that yield increased with improved adaptation.

Heterosis. Heterosis, or hybrid vigor, has frequently been exploited in tree breeding programs ( $\mathrm{Li}$ and $\mathrm{Wu}, 1997)$. It is described as the superiority of hybrids for a trait over the midparent value or the better parent value (Hayes, 1952). These notations were observed in the present study, but with parental provenances substituted for parents in the strict sense. The offspring of both intra and intersubspecific hybrids displayed heterosis for yield and hardiness on the basis of mid-provenance values (Fig. 2A and B). On the basis of the better provenance value, intrasubspecific hybrids (Fin $x$ Dan) showed strong heterosis for both yield and Wd, as did intersubspecific hybrids Fin x Chi, while Dan x Chi displayed heterosis for Wd but not for yield. Heterosis for yield and Wd was also observed in the two Russian related hybrid groups in relation to the mean of the single known provenance control (Fig. 2C and D). Our results generally support Lerner's (1954) genetic homeostasis theory that hybrids are better buff-

Fig. 1. Mean berry yield and winter hardiness among offspring groups and parental controls. Berry yield and winter hardiness are scored on scales of 0 to 5 and 1 to 5 , with larger numbers representing higher berry yields and winter hardiness, respectively. Extensions of bars are SD values. Bars marked by the same letters are not significantly different at $P=0.05$ for berry yield (lower case) and winter hardiness (upper case), respectively.

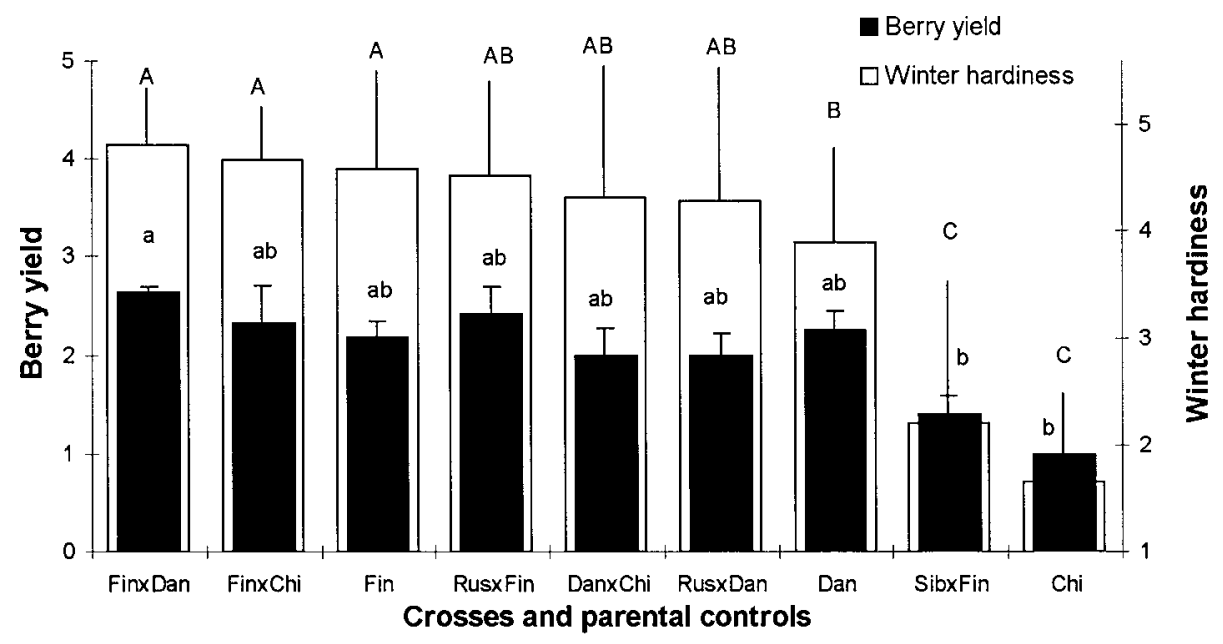


A On basis of mean parent

value of yield

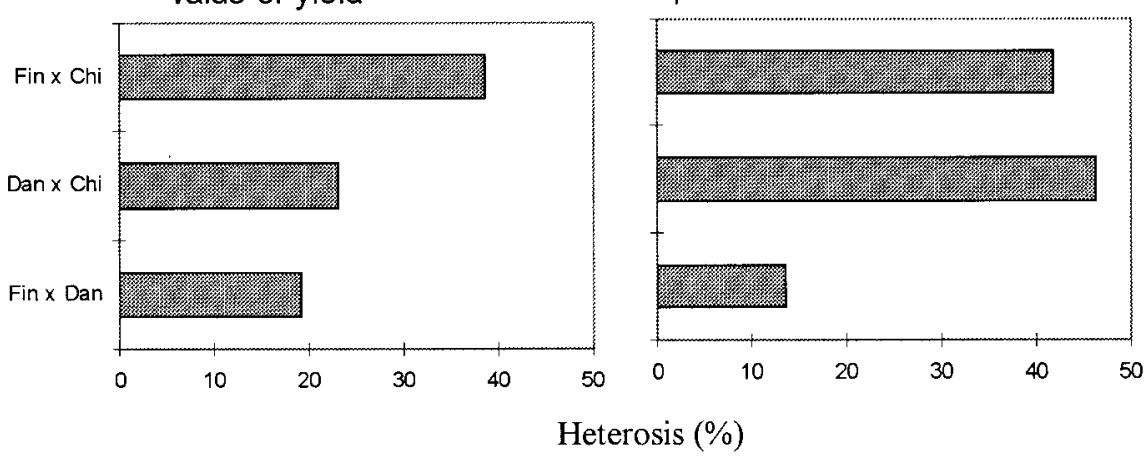

C On basis of single parent value of yield

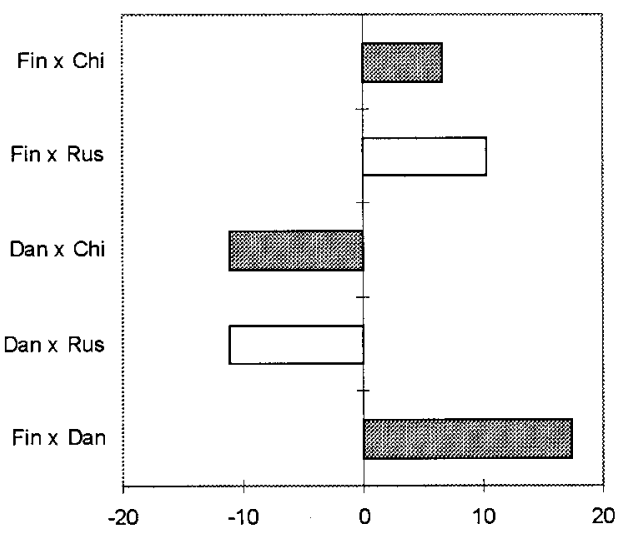

B On basis of mean parent value of hardiness

D On basis of single parent value of hardiness

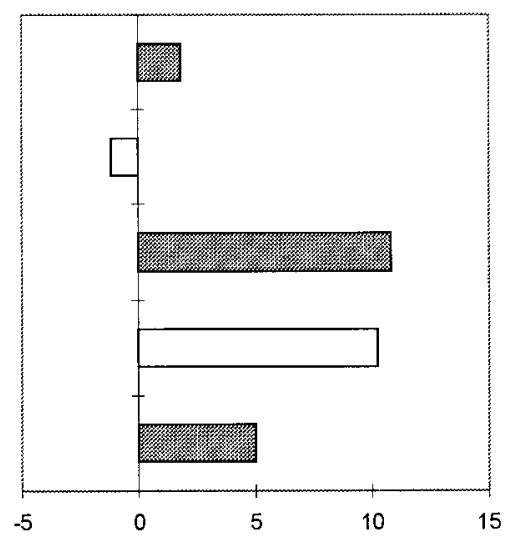

Heteroisi (\%)

Fig. 2. Heteroses based on midparental value for $(\mathbf{A})$ berry yield and (B) winter hardiness and based on the better maternal parent or know maternal parent value for $(\mathbf{C})$ berry yield and (D) winter hardiness.

ered against challenging environments than the parents. According to the theory, hybrids will have an advantage over their parents for specific biochemical pathways across different environments, which has been confirmed by several studies (Barlow,

1981; Clare and Luckinbill, 1985). However, heterosis is species, provenance and location dependent (Campbell et al., 1993; $\mathrm{Li}$ and $\mathrm{Wu}, 1997)$. For instance, in our study, Sib $x$ Fin demonstrated no, or negative heterosis for yield and hardiness (Fig. 1).

Heritabilities AND STABILITIEs. Estimates of heritabilities and repeatabilities for offspring from Fin $x$ Dan are listed in Table 2. The start of flowering (Fs) showed a moderate heritability $\left(\mathrm{h}^{2}=0.44\right)$, while heritability was weak $\left(\mathrm{h}^{2}=0.20\right)$ for the end of flowering $(\mathrm{Fe})$. These two parameters are subject to relatively strong parental interaction. Their relatively low heritability coupled with moderate nonadditive variance implies that $\mathrm{Fs}$ and $\mathrm{Fe}$ are difficult to predict in offspring. The duration of flowering $(\mathrm{Fd})$ had a weak heritability $\left(\mathrm{h}^{2}=0.23\right)$ which was virtually due only to maternal influence. In almond [Prunus dulcis (Mill) D.A. Webb], this character was observed to be highly influenced by environmental factors (Dicenta et al., 1993).

The maturity parameters, Ms and Mh, had strong heritabilities with a predominantly matroclinal inheritance. This finding suggests that inheritance of Ms and Mh may be sex-linked or cytoplasmic, and that selection of female bushes for these two traits would be quite efficient.

Heritability for Mf was larger in $1999\left(\mathrm{~h}^{2}\right.$ $=0.51)$ than in $2000\left(\mathrm{~h}^{2}=0.34\right)$, but neither was strong, nor was its combined value large $\left(h^{2}=0.41\right)$ for the 2 years. In contrast, the variance of Mf was due mainly to genetic factors in almond (Dicenta et al., 1993) and peach [Prunus persica (L.) Batsch (Peach Group)] (de Souza et al., 1998). The high heritability for date of maturity in peach is attributed to major gene action by Hesse (1975). The low heritability for Mf found in our study suggests that this character may be controlled by more genes in sea buckthorn than in almond or peach, since no interaction of maturity with years was found $\left(\mathrm{r}_{B}=1.00\right)$.

Table 2. Heritability ${ }^{\mathrm{z}}( \pm \mathrm{SE})$ and stability based on 312 bushes of intrasubspecific progenies (Fin $\mathrm{x}$ Dan) over 2 years.

\begin{tabular}{llcccc}
\hline \hline Year & Traits & Hd $(\%)$ & $\mathrm{h}_{\mathrm{f}}^{2}$ & $\mathrm{~h}_{\mathrm{m}}^{2}$ & $\mathrm{~h}^{2}$ \\
\hline 1999 & Start of flowering & $16.92 \pm 19.08$ & $0.47 \pm 0.31$ & $0.39 \pm 0.30$ & $0.44 \pm 0.16$ \\
& End of flowering & $34.54 \pm 25.07$ & $0.23 \pm 0.23$ & $0.15 \pm 0.19$ & $0.20 \pm 0.12$ \\
& Duration of Flowering & $6.57 \pm 14.75$ & $0.36 \pm 0.25$ & $0.00---$ & $0.23--$ \\
& Start of maturity & $4.05 \pm 12.59$ & $1.30 \pm 0.62$ & $0.16 \pm 0.13$ & $0.88 \pm 0.27$ \\
& Half maturity & $9.79 \pm 13.60$ & $1.18 \pm 0.58$ & $0.16 \pm 0.14$ & $0.81 \pm 0.25$ \\
& Full maturity & 0.00 & $0.61 \pm 0.34$ & $0.33 \pm 0.24$ & $0.51 \pm 0.17$ \\
& Duration of maturity & 0.00 & $0.16 \pm 0.15$ & $0.22 \pm 0.18$ & $0.18 \pm 0.09$ \\
& Reproductive duration & 0.00 & $0.64 \pm 0.36$ & $0.09 \pm 0.11$ & $0.44 \pm 0.16$ \\
& Yield & 0.00 & $0.23 \pm 0.15$ & $0.38 \pm 0.28$ & $0.29 \pm 0.10$ \\
& Winter damage & 0.00 & $0.04 \pm 0.10$ & $0.00--$ & $0.02--$ \\
& Full maturity & 0.00 & $0.32 \pm 0.20$ & $0.38 \pm 0.28$ & $0.34 \pm 0.12$ \\
& Yield & 0.00 & $0.06 \pm 0.12$ & $0.71 \pm 0.46$ & $0.29 \pm 0.11$ \\
& Full maturity & $7.80 \pm 9.71$ & $0.47 \pm 0.24$ & $0.31 \pm 0.21$ & $0.41 \pm 0.13$ \\
& Yield & 0.00 & $0.12 \pm 0.12$ & $0.43 \pm 0.28$ & $0.23 \pm 0.08$ \\
\end{tabular}

$\overline{\mathrm{z}} \mathrm{Hd}$ represents the ratio of dominant effects (nonadditive effects, $4 \sigma_{\mathrm{D}}^{2}$ ) to phenotypic variance; $\mathrm{h}_{\mathrm{f}}{ }_{\mathrm{f}}, \mathrm{h}_{\mathrm{m}}{ }_{\mathrm{m}}$, and $\mathrm{h}^{2}$ represent heritabilities due to maternal, paternal and family contributions, respectively. 
Table 3. Genetic correlations ( $r_{\mathrm{a}}$ : below diagonal) and phenotypic correlations ${ }^{\mathrm{z}}\left(r_{\mathrm{p}}\right.$ : above diagonal) among characters based on progenies of Fin $x$ Dan.

\begin{tabular}{|c|c|c|c|c|c|c|c|c|c|}
\hline Traits & $\begin{array}{l}\text { Flower } \\
\text { start }\end{array}$ & $\begin{array}{l}\text { Flower } \\
\text { end }\end{array}$ & $\begin{array}{l}\text { Flower } \\
\text { duration }\end{array}$ & $\begin{array}{l}\text { Maturity } \\
\text { start }\end{array}$ & $\begin{array}{c}\text { Half } \\
\text { maturity }\end{array}$ & $\begin{array}{c}\text { Full } \\
\text { maturity }\end{array}$ & $\begin{array}{l}\text { Maturity } \\
\text { duration }\end{array}$ & $\begin{array}{l}\text { Reproductive } \\
\text { duration }\end{array}$ & Yield \\
\hline Start of flowering & $\begin{array}{ll}-- \\
--\end{array}$ & $0.63^{*}$ & -0.30 & $0.47^{*}$ & $0.50^{*}$ & $0.41^{*}$ & 0.14 & -0.31 & -0.20 \\
\hline End of flowering & $0.80^{* *}(0.17)$ & --- & $0.55^{*}$ & $0.45^{*}$ & $0.45^{*}$ & $0.42^{*}$ & 0.18 & -0.03 & -0.07 \\
\hline Duration of flowering & $-0.48^{*}(0.30)$ & $0.19(0.48)$ & --- & 0.05 & 0.03 & 0.08 & 0.07 & 0.29 & 0.10 \\
\hline Start of maturity & $0.59^{*}(0.21)$ & $0.80^{* *}(0.16)$ & $0.16(0.31)$ & -- & $0.96^{* *}$ & $0.79^{* * *}$ & 0.20 & $0.48^{*}$ & -0.34 \\
\hline Half maturity & $0.64^{*}(0.20)$ & $0.76^{* * *}(0.18)$ & $0.10(0.32)$ & $1.00^{* * *}(0.00)$ & --- & $0.85^{* *}$ & 0.33 & 0.53 & -0.35 \\
\hline Full maturity & $0.60^{*}(0.22)$ & $0.60^{*}(0.26)$ & $-0.06(0.33)$ & $0.94^{* *}(0.05)$ & $0.96^{* *}(0.03)$ & --- & $0.77^{* *}$ & $0.76^{* *}$ & -0.23 \\
\hline Duration of maturity & $0.30(0.39)$ & $-0.08(0.52)$ & $-0.49(0.32)$ & $0.27(0.33)$ & $0.34(0.32)$ & $0.62^{*}(0.24)$ & --- & $0.71^{* * *}$ & -0.02 \\
\hline Reproductive time & $-0.12(0.35)$ & $0.10(0.44)$ & $0.33(0.31)$ & $0.64^{*}(0.19)$ & $0.63^{*}(0.19)$ & $0.73^{* *}(0.17)$ & $0.54^{*}(0.29)$ & --- & -0.13 \\
\hline Yield & $-0.34(0.31)$ & $-0.48^{*}(0.33)$ & $-0.20(0.33)$ & $-0.55^{*}(0.20)$ & $-0.53^{*}(0.21)$ & $-0.73^{* *}(0.15)$ & $-0.72^{* * *}(0.19)$ & $-0.62^{*}(0.20)$ & --- \\
\hline
\end{tabular}

${ }^{\mathrm{z}}$ Correlation values $\left(r_{\mathrm{a}}\right.$ or $\left.r_{\mathrm{p}}\right) \geq 0.70 ; 0.69 \geq r_{\mathrm{a}}$ or $r_{\mathrm{p}} \geq 0.40$; and $r_{\mathrm{a}}$ or $r_{\mathrm{p}}<0.40$ were considered strong or very strong, moderate, and weak, respectively. Correlation values $\geq 0.70$ are marked by $* *$, while correlation values $\geq 0.40$ but $\leq 0.69$ are marked by $*$. Numbers in parentheses are the sE of genetic correlations.

Duration of maturity $(\mathrm{Md})$ represents uniformity in ripening, which is an important indicator of berry quality in sea buckthorn production. At high latitude, a short entire reproductive time (Rt) is desirable for the berries to mature before temperatures fall too low. Both characters are highly susceptible to environmental variation. The analogous character to Rt in peach and almond was highly heritable (de Souza et al., 1998; Dicenta et al., 1993). The low heritability of $\operatorname{Rt}\left(\mathrm{h}^{2}=0.44\right)$ in sea buckthorn suggests that the genetic basis may be different, but the finding could also reflect a more fluctuating climatic situation within the growing season.

Yield showed weak heritabilities, whether these were estimated separately or combined for the 2 years. This heritability was attributed more to paternal than to maternal factors. Especially in 2000 , there were almost no maternal factors contributing to the heritability. The low maternal heritability implies that selection based on yield performance of female bushes will be inefficient in sea buckthorn breeding. However, the low heritability could also be due to selection of female parents, which reduces maternal variance, and consequently the covariance between their offspring (Dicenta et al., 1993; Li and Wu, 1997).

Heritability of winter hardiness $\left(h^{2}=0.02\right)$ was found to be very low in our study. This is very likely because native sea buckthorns have adapted to high latitude environmental conditions (Lindèn et al., 1999). The offspring of Fin x Dan used for our heritability study was found to be more winter hardy than their native parental controls (Figs. 1 and 2). However, the climate at the testing site was not severe enough to differentiate the variation in winter damage among half sibs or full sibs.

GENETIC AND PHENOTYPIC CORRELATIONS. As shown in Table 3, the genetic correlations among most characters were stronger than the corresponding phenotypic correlations. Our results were concordant with the findings in peach (de Souza et al., 1998), where the phenotypic variation included large contributions from environmental effects.

The start of flowering (Fs) correlated moderately strongly or strongly, both genetically and phenotypically, with the end of flowering ( $\mathrm{Fe}$ ) and full maturity (Mf), indicating that late flowering in associated with late ripening. This trend makes it difficult to combine late flowering and early maturation in sea buckthorn. However, Fs correlated negatively with the duration of flowering $(\mathrm{Fd})\left(\mathrm{r}_{\mathrm{G}}=-0.48\right)$ and reproductive time $(\mathrm{Rt})\left(\mathrm{r}_{\mathrm{G}}=-0.12\right)$, indicating that later flowering tended to associate with a short $\mathrm{Fd}$ and short Rt. These results are in agreement with the observation that the lengths of different developmental periods are highly correlated with their corresponding temperature in peach (Boonprakob et al., 1992). Early flowering individuals develop slowly at the relatively cool temperatures after flowering, compared to late flowering individuals. However, the efficacy of Fs in predicting Rt is largely offset by the cooler temperatures experienced by the late ripening individuals as compared with the early ripening individuals in sea buckthorn. The strong correlation between Rt and $\mathrm{Mf}\left(\mathrm{r}_{\mathrm{G}}=0.73\right.$ and $\left.\mathrm{r}_{\mathrm{P}}=0.76\right)$ indicates that $\mathrm{Mf}$ is a much better predictor of Rt than is Fs.

Mf correlated, both genetically and phenotypically, very strongly with the start of maturity (Ms) and half maturity (Mh). This suggests that these three maturity-related characters were controlled by the same genes. Mf also correlated moderately strongly with $\mathrm{Md}$, indicating that later ripening is associated with a longer time for maturation, and a longer time for the entire reproductive period as well.

Moderate to strong negative genetic correlations characterized well the relationships between yield and most other characters, but phenotypically these relationships were much weaker. These results are in agreement with the observation that yield was associated strongly with environmental effects as shown by its low heritability. The strong negative genetic correlation between yield with Mf shows that the earlier the maturation, the higher the yield. This finding is not unexpected in high latitude regions, since late ripening individuals may not have enough energy, after attaining berry maturation, for forming sufficient flower primordia for the following yield.

\section{Conclusions and Considerations}

The characters considered in this study were found to be quantitatively inherited. Intersubspecific offspring resembled their ssp. rhamnoides maternal controls for most characters related to flowering and maturity. This implies that Finnish and Danish provenances showed dominance over ssp. sinensis or provenances from Russia (ssp. turkestanica). The improvement of yield in intersubspecific crosses was associated with an increase in their adaptability.

Hybrids within ssp. rhamnoides were better buffered against environmental fluctuations than their parental controls, but the climate at the testing site was not severe enough to differentiate the degree of winter damage among half sibs or full sibs. Heritabilities for most flowering and maturity-related characters ranged from low to intermediate, indicating the importance of environmental contributions to the phenotypic variation. This in turn explains why most genetic correlations were higher than their 
corresponding phenotypic correlations. Later flowering tends to delay maturity, but also shortens the duration of flowering. A carefully maintained balance between later flowering and shorter flowering duration should allow breeders to aim for earlier maturity which, in its turn, is useful for yield improvement.

Our analyses were only based on a small scale mating design at a single test site. The results should be interpreted cautiously when applied to practical breeding programs. A single test site will not allow genetic and environmental interaction to be estimated (Becker, 1992). However, the estimates of effects of years would be useful as references of environmental effects.

A small sampling size might result in biased estimates of genetic parameters (Jensen and Barr, 1971). This was clearly demonstrated by the large SE values involved in estimates of heritabilities for, and genetic correlations between, most of the characters recorded in the present study. In tree fruit breeding, since the trees have to be widely spaced, it is usually not feasible to plant large number of trees. According to Jensen and Barr (1971), for a given size of a plantation, increasing the number of parental combinations can improve reliability of heritability estimates and hence of the genetic correlation when ANOVA are used, especially for a limited sample size. This would be a way for breeders to plan a breeding program with limited resources.

\section{Literature Cited}

Barlow, R. 1981. Experimental evidence for interaction between heterosis and environment in animals. Animal Breeding Abstr. 49:715-737.

Becker, W.A. 1992. Manual of quantitative genetics. 5th ed. Academic Enterprises, Pullman, Wash.

Boonprakob, U., D.H. Byrne, and R.E. Rouse. 1992. Response of fruit development period to temperature during specific periods after full bloom in peach. Fruit Var. J. 46:137-140.

Campbell, J.S., J.M. Mahoney, and B.R. Rood. 1993. A lack of heterosis in natural poplar hybrids from southern Alberta. Can. J. Bot. 71:37-42.

Clare, J.M. and L.S. Luckinbill. 1985. The effects of gene-environment interaction on the expression of longevity. Heredity 55:19-26.

de Souza, V.A.B., D.H. Byrne, and J.F. Taylor. 1998. Heritability, genetic and phenotypic correlations, and predicted selection response of quantitative traits in peach: II. Analysis of several fruit traits. J. Amer. Hort. Sci. 123:604-611.

Dicenta, F., J.E. Garcia, and E.A. Carbonell. 1993. Heritability of flowering, productivity and maturity in almond. J. Hort. Sci. 68:113120.

Falconer, D.S. and T.F.C. Mackay. 1996. Introduction to quantitative genetics. 4th ed. Longman Scientific and Technol, London.

Hayes, H.K. 1952. Development of the heterosis concept, p. 49-65. In: J.W. Gowen (ed.). Heterosis. Iowa State Univ. College Press, Ames. Hesse, C.O. 1975. Peaches, p. 285-335. In: J. Janick and J.N. More (eds.). Methods in fruit breeding. Purdue Univ. Press, West Lafayette, Ind.

Hill, J., H.C. Becker, and P.M.A. Tigerstedt, 1998. Quantitative and ecological aspects of plant breeding. Chapman \& Hall, London

Jensen, E.L. and G.R. Barr. 1971. Stardard errors of heritability estimates calculated from variance component analysis of a two way classification. Animal Sci. 32:1069-1077.

Lerner, I.M. 1954. Genetic homeostasis. Oliver and Boyd, Edinburgh, United Kingdom.

Li, B. and R. Wu. 1997. Heterosis and genotype $\times$ enviroment interactions of juvenile aspens in two contrasting sites. Can. J. For. Res. 27:1525-1537.

Lindèn, L., P. Lalonen, M. Seppänen, and A. Väinölä. 1999. Cold hardiness research on agricultural and horticultural crops in Finland. Agr. Food Sci. Finland 8:459-477.

Nesterov, Y.S. 1983. Geographical variation in rhythm of the annual life cycle in apple varieties (in Russian, summary in English). Trudy po prikladnoi botanike genetike i selektssi 79:129-138.

SAS Institute Inc. 1996. SAS software. Version 6.12. SAS Inst. Cary, N.C.

Tang, X., N. Kälviäinen, and H. Tuorila. 2001. Sensory and hedonic characteristics of sea buckthorn (Hippophae rhamnoides L.) juice. Lebensmittel-Wissenschaft und-Technologie (lwt)-Food Sci. and Tech. 34:102-110

Tang, X. and P.M.A. Tigerstedt. 2001. Variation of physical and chemical characters within an elite sea buckthorn (Hippophae rhamnoides L.) breeding population. Scientia Hort. 88:203-214.

Tigerstedt, P.M.A. 1994. Adaptation, variation and selection in marginal areas. Euphytica 77:171-174.

Väinölä, A. and P. Joy. 1996. Breeding woody ornamentals for northern climates. Plant Breeding Abstr. 5:601-607.

Vanninen, I., S. Laakso, and M. Raatikainen. 1988. Geographical variation in the phenology and morphology of bilberry in Finland. Acta Bot. Finn. 136:49-59.

Yamada, Y. 1962. Genotype by environmental interaction and genetic correlation of the same trait under different environments. Jpn. J. Genet. 37:498-509.

Yao, Y. 1994. Genetic diversity, evolution and domestication in sea buckthorn (Hippophae rhamnoides L.). PhD diss. Univ. of Helsinki, Helsinki, Finland.

Yao, Y. and P.M.A. Tigerstedt. 1995. Geographical variation of growth rhythm, height and hardiness, and their relations in Hippophae rhamnoides. J. Amer. Soc. Hort. Sci. 120:691-698. 